\title{
An Automatic Irrigation System using WIFI in Wireless Sensor Network
}

\author{
Mr. Ganesh Kumar M T ${ }^{1}$, Sachin Athreya $D^{2}$, Rashmi H C ${ }^{3}$, Sowmya ${ }^{4}$, Shashidhar K $\mathbf{P}^{5}$ \\ Professor, ECE, GMIT, Mandya, India ${ }^{1}$ \\ $8^{\text {th }}$ Sem, Electronics and Communication Engineering, GMIT, Mandya, India ${ }^{2,3,4,5}$
}

\begin{abstract}
The project is designed to develop an automatic irrigation system that switches a pump motor ON/OFF by sensing the moisture content of the soil using wireless technology effectively for agriculture applications through wifi module used in sending an SMS on the status. In the field of agriculture, use of proper method of irrigation is important. The advantage of using this method is to reduce human intervention and to ensure proper irrigation. The project uses ESP8266 MOD which is programmed to receive the input signal of varying moisture condition of the soil through sensing arrangement. Once the module receives this signal, it generates an output that drives a relay for operating the water pump. This concept in future can be enhanced by integrating XBEE/Bluetooth technology, such that whenever the water pump switches ON/OFF, the information is sent to a smart mobile phone or XBEE transceiver module regarding the status of the pump.
\end{abstract}

Keywords: Energy consume, Humidity sensor, Soil moisture sensor, Temperature sensor, wireless sensor network.

\section{INTRODUCTION}

Agriculture plays a vital role in every countries economy Generally agriculture uses $80 \%$ of fresh water this percentage will be dominant in water consumption because of population growth so this becomes a very important to create a system which is based on science and technology for sustainable use of water.There are so many systems are available to achieve water savings in various crops from basic ones to more technologically advanced ones .In one system plant water status was monitored and it is based on canopy temperature of the plant, another system was developed to arrange irrigation of crop water stress index .This paper uses a low cost wireless device for data communication .An automated irrigation system is developed with a low cost moisture sensor.In environmental application, sensors network have been used to monitor a variety of environmental parameters or conditions in marine, soil and atmospheric conditions. Application in agriculture have been used to provide data for appropriate management .Various commercial WSNs exist, ranging from limited and low resolution devices with sensors and embedded processors .In a wireless node, the radio modem consumes more power.

Recently there are too many wireless standard have been established such as local area network uses IEEE $802.11 \mathrm{~b}$ (Wi-Fi) and wireless personal area network uses IEEE 802.15.1 (WPAN), IEEE 802.15.1 (Bluetooth) and IEEE 802.15.4 (XBee). In this paper development of an automated irrigation system based on Wi-Fi and wireless communication is presented. The aim of this implementation is to reduce the water use using an automatic irrigation system .In this implementation we are using a 3 sensors i.e. soil moisture sensor, temperature sensor, Humidity sensor this 3 sensors are interface with ESP8266MOD where we are transmitting the soil data to the PC using transreciever and also we are using a motor for watering the field. 3 sensors are deployed in plant root zone .If soil is dry automatically motor will get on in this way soil moisture sensor provide quick information to the. MODULE. Communication between the sensor node and data receiver is via the internet protocol. This data is given to the PC via wi-fi and we are using adafruit software for display purpose.

\section{RELATED WORK}

Irrigation can be broadly defined as the practice of applying additional water (beyond what is available from rainfall) to soil to enable or enhance plant growth and yield, and, in some cases, the quality of foliage or harvested plant parts. The water source could be groundwater pumped to the surface, or surface diverted from one position on the landscape to another. Development of irrigation water often entails development of large-scale, geographically significant dams and water impoundments and/or diversions that can provide additional functions apart from crop growth enhancement, e.g., flood control, recreation, or generation of electricity [5]. In many cases sustainable irrigation development requires concomitant development of surface and/or subsurface drainage. 


\section{IJIREEICE

Irrigation may be the single most strategically important intentional environmental modification humans have learned to perform [5]. While irrigation's impact has not always been as critical to the global agricultural economy and food supply as it is today, it has always had major local impacts and profound historical and social consequences. In the Bible's book of Genesis, we are told that God's creation of humans was accompanied shortly thereafter by His assignation to Adam of the stewardship of the irrigated orchard that was Paradise. The four life giving water heads of Judeo-Christian Paradise are also mentioned in the 47th Sura of the Koran.

In the ancient world, the level of irrigation sophistication varied from one setting to the next. The differences, however, stemmed mostly from variations in understanding of both large- and small-scale hydraulic principles, as well as the capabilities to construct feats of hydraulic engineering. The Assyrians, for example, built an inverted siphon into the Nineveh Aqueduct 700 years before the birth of Christ, an engineering feat unrivaled until the 1860 construction of the pressurized siphons of the New York Aqueduct.

Some ancient irrigation schemes have survived to the present day where geologic, soil, and climatic conditions were favorable and where then-known management principles were adequate for the prevailing conditions. However, some ancient schemes failed. In the Mesopotamian Valley, Syria, Egypt, and other areas throughout the Middle East, there were many cases where the principles of salt management and drainage were insufficiently understood, resulting in eventual permanent impairment of the land .

The mid-19th century marked a conjunction of several ascending areas of scientific learning, including chemistry, physical chemistry, physics, mineralogy, and biology. These were adapted, blended, and applied in important emerging new sub-disciplines of soil chemistry, soil physics, plant physiology, and agronomy, whose fundamental principles were to prove essential for sustainable irrigation system design and operation.

The development of WSNs based on microcontrollers and communication technologies can improve the current method of monitoring to support the response appropriately in real time for a wide range of applications. One of the systems is the 8051 controller based system [1]. The moisture sensor is placed in field and sends information to ADC. From ADC to the microcontroller. The controller data are displayed in the LCD [2].

The second system uses WSNs and GPS. The system consists of five in-field sensing stations distributed across the field, an irrigation control station, and a base station. The in-field sensing stations monitor the field conditions of soil moisture, soil temperature, and air temperature. All in-field sensory data are wirelessly transmitted to the base station. The base station processes the in-field sensory data through a user-friendly decision making program and sends control commands to the irrigation control station [3]. The irrigation control station updates and sends geo referenced locations of the machine from a differential GPS mounted at the cart to the base station for real-time monitoring and control of the irrigation system.

The third system consists of temperature sensor (LM 35), water level sensor, humidity sensor (SY-HS-220) and PIR sensor v-11(\#555-28027) to monitor the minute to minute status of the field to help the farmer to maintain his fields with better technology $\mathrm{n}$ increase his production value. The system is divided into three segments such as sensor node, wireless transmission and user module [4]. It is a GSM based system so through the GSM data are transmitted to the computer.

\section{METHODOLOGY}

Below figure shows the design sequence for the proposed system. The proposed system design sequence is divided into two methods one is Top-Down and other is Bottom Up method.

The design process of the proposed system is divided into five levels and they are as follows.
A. Requirement Level
B. Specification Level
C. Architecture Level
D. Component Level
E. Integration Level
F. Application Level

\section{BELOW FIGURE SHOWS THE DESIGN SEQUENCE FOR THE PROPOSED SYSTEM.}




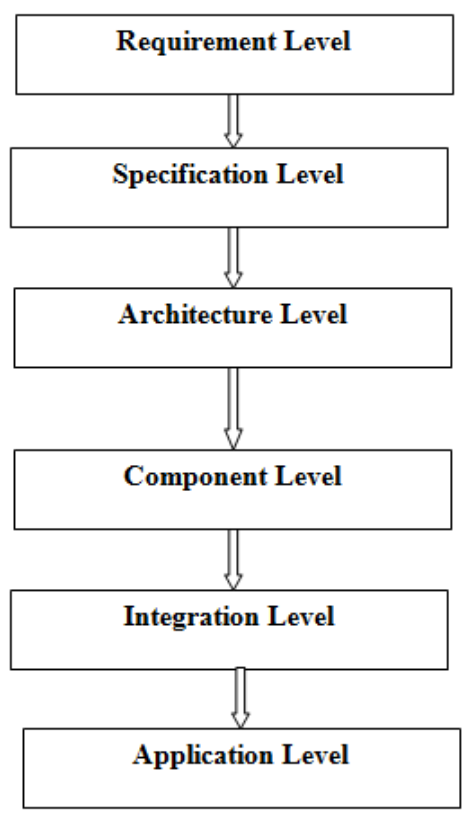

Fig1. Design sequence of proposed automatic irrigation system.

\section{A. Requirement Level}

It is a first level of the design process of proposed an automatic irrigation system it is divided into two types and they are as follows

\section{Functional requirement}

Functional requirements consist of technical details, data manipulation and processing, sensing and indication. The proposed system uses a sensing device to detect soil moisture, temperature and humidity. It uses an automatic indication to detect an automatic operation such as Motor Pump, Fan (ON/OFF),Buzzer Blow.

\section{Non functional requirement}

It is mutually exclusive of functional requirement. The proposed system consists of monitoring and controlling water level of soil, environmental temperature and humidity. When this factor crosses the threshold value of particular crop it automatically start respective operation of Pump, Fan and Buzzer.

B. Specification Level

Specification is a detailed assessment of requirements of devices. The table gives a specification of devices used

TABLE I DEVICES SPECIFICATION

\begin{tabular}{|c|c|c|}
\hline Sl. no & Devices & Specification \\
\hline 1 & Wi-Fi module & ESP8266 \\
\hline 2 & MOSFET ,AND gate & $5 \mathrm{v}-10 \mathrm{v}$ \\
\hline 3 & Sensors & LM-35, SY-HS-220 soil moisture \\
\hline
\end{tabular}

\section{Architecture Level}

\section{FLOWCHART}

The algorithm for the proposed design is shown in the Figure 1. The sensor which is placed at field station is power up with DC power. At particular area in field the temperature and moisture of the soil is given by temperature sensor and soil moisture sensor respectively. And the values are transferred to base station in particular time intervals. The base station receives the data sent by field station and correlated with predefined set points are programmed in the base station. When the collected value is higher than the set points the valve of watering system is activated. The value monitored by the sensors is uploaded in web by using ESP8266 Wi-Fi module. Wherever the user, continuous monitoring of the behavior of the soil is possible by Internet of Things (IOT). 


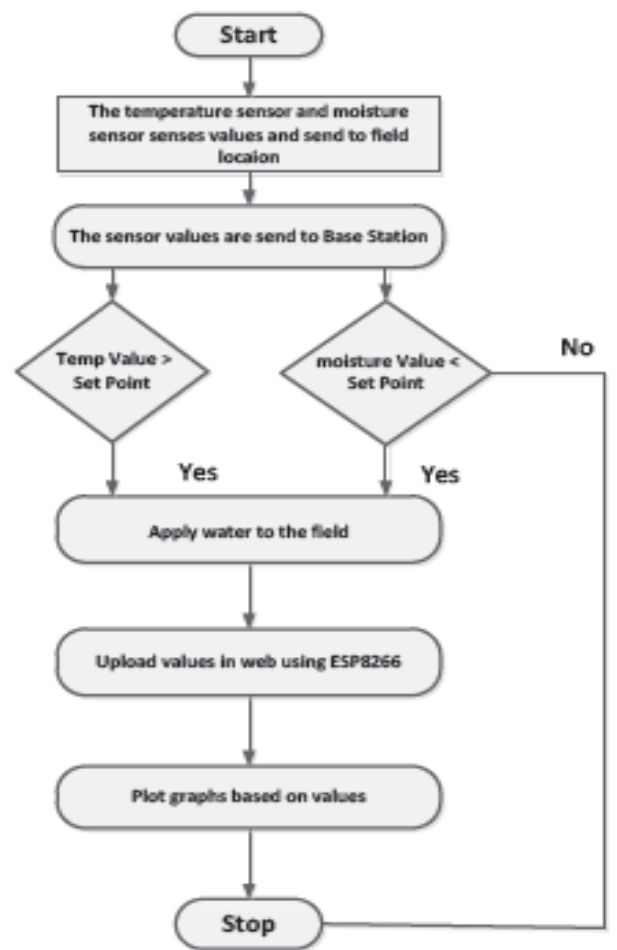

Figure.2

Block diagram

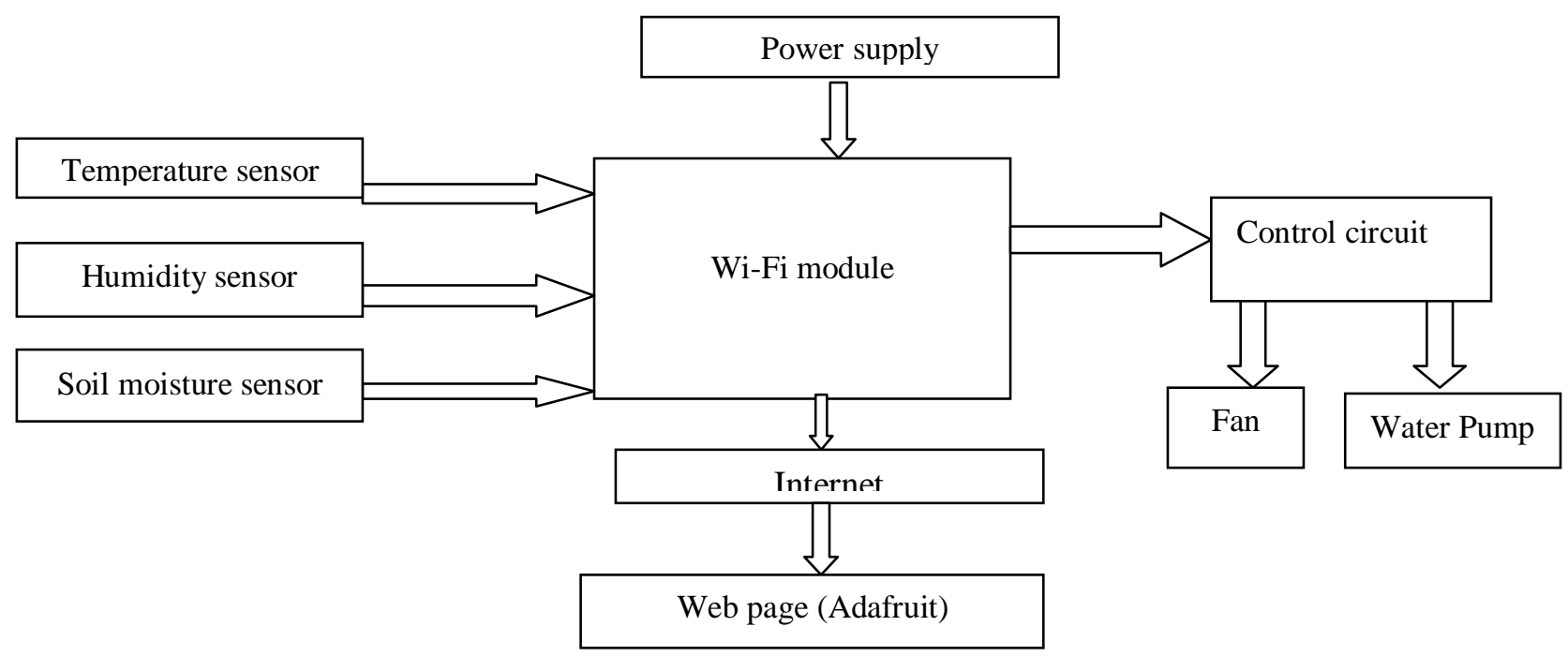

Figure. 3 block diagram

D. Component Level

It is an important and independent part of system which performs the function in the architecture .It is the most important level for the design of the system. It consist of hardware and software component

I. Hardware component

Hardware component is a physical device that is a part of the system which connects the other component, provide input and output to and from the application. The proposed system hardware components are Temperature sensor, humidity sensor, soil moisture sensor, WI-FI module, MOSFET, AND gate, Fan, Motor pump, Buzzer, Relay

II. Software component

It is interfaced between the hardware and PC. The features are inbuilt in a software application is called as a software component 


\section{International Journal of Innovative Research in} Electrical, Electronics, Instrumentation and Control Engineering

\section{ISO 3297:2007 Certified}

Vol. 5, Issue 6, June 2017

F. Application Level

G. The proposed system is applied in agriculture field to detect the temperature, humidity, moisture, which will improve the quality and quantity of crop productions.

\section{RESULT}

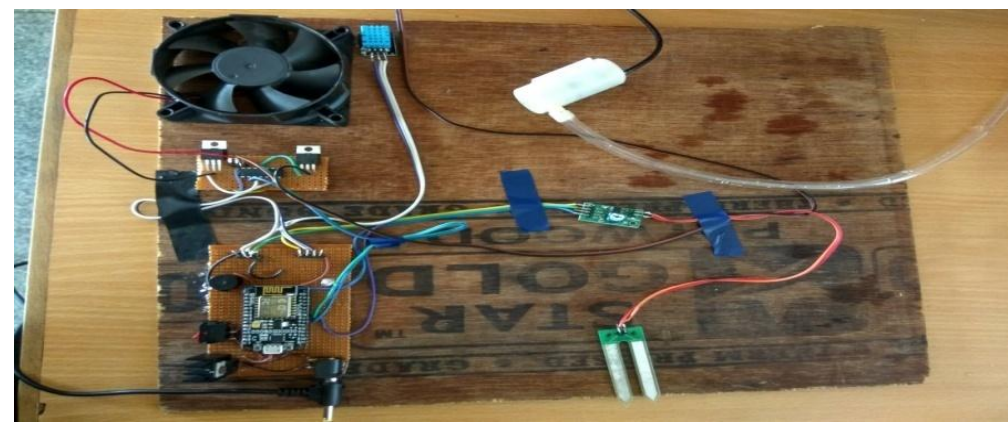

Figure.4 System hardware setup
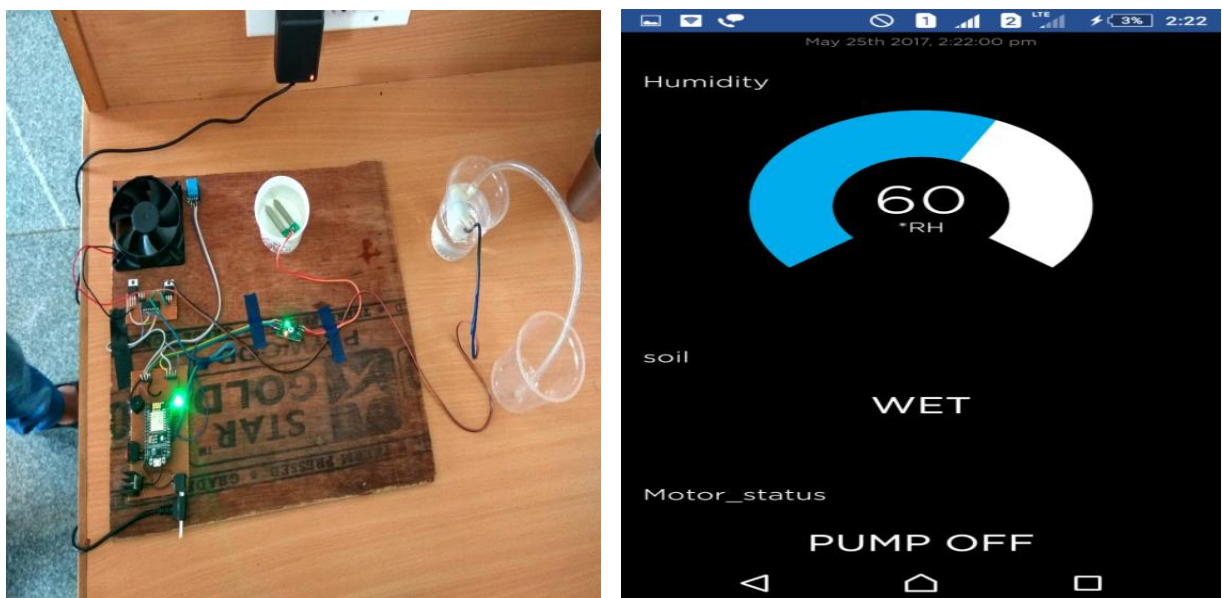

Figure.5 Computer monitoring system connected with master node with wet
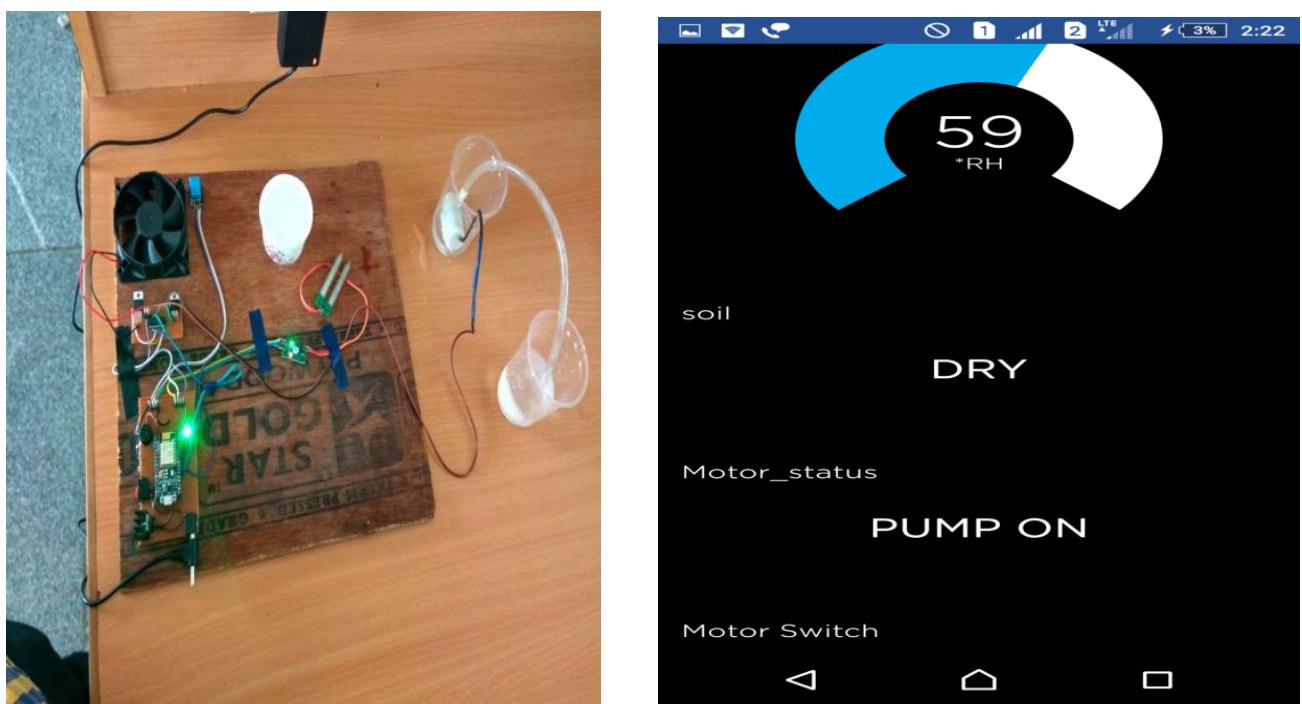

Figure.6 Computer monitoring system connected with master node with wet

The farmer has the ability to Monitor the Sensors information at his/her home, the sensor information displays on the master node LCD as well as PC Soil moisture, temperature and humidity sensor fixed in the field sense the actual values. These values are compared with the threshold values. 


\section{IJIREEICE \\ Vol. 5, Issue 6, June 2017}

If the actual value crosses the threshold values then corresponding pump, fan or Buzzer switched ON

\section{CONCLUSION}

The automation in irrigation system applied was once located to be appropriate and price adequate for accessing water source of supply for agricultural management. This irrigation method permits farming in areas with water scarcity thereby making improvements to hold water The irrigation system scheme can be conformed to an assortment of particular harvest needs and requires least preservation. The standard structure of the irrigation system which is automated permits it to be range up for bigger nurseries or open gardens As the insistence for water increments, alongside the need to ensure floating natural surroundings, water protection rehearses for irrigation system should be powerful and moderate. Accuracy minimizing so as to water system will enhance irrigation system the misuse of water, and efficiency, while expand crop yields. The best strategy for deciding the water requests of harvests is based on the real time controlling of soil moisture.

\section{REFERENCES}

[1] Joaquin Gutierrez, Juan Francisco Villa-Medina, Alejandra Nieto-Garibay, and Miguel Angel Porta-Gandara"Automated Irrigation System using WSNs and GPRS Module" IEEE transactions on instrumentation and measurement 2014.

[2] Abhinav Rajpal, Sumit Jain, Nistha Khare and Anil Kumar Shukla "Microcontroller based automatic irrigation system with moisture sensors", International Conference on Science and Engineering (ICSE 2011.

[3] Yunseop (James) Kim, Member, IEEE, Robert G. Evans, and William M. Iversen "Remote sensing and control of an irrigation system usng a distributed wireless sensor network", IEEE Transaction on instrumentation and measurements 2008.

[4] Mr.K.Kirubakaran, Selvi Ramalingam, S. Meerabai, V.Preethi "Surveillance and steering of agricultural field using ZigBee", International journal on recent and innovation trends in computing and communication 2013.

[5] R.E. Sojka, D.L. Bjorneberg, and J.A. Entry" Irrigation: an historical perspective "Soil Scientist, Irrigation Engineer, and Soil Microbiologist, Kimberly, Idaho, U.S.A.

\section{BIOGRAPHIES}

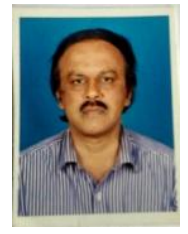

Mr. Ganesh Kumar M T, Professor, Electronics and communication Dept., G Madegowda Institute of Technology, Bharathinagara (K M Doddi), Mandya

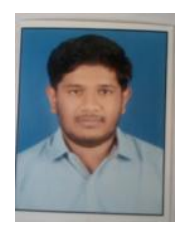

Mr. Sachin Athreya .D, 8TH Semester, Electronics and communication Dept., G Madegowda Institute of Technology, Bharathinagara (K M Doddi), Mandya

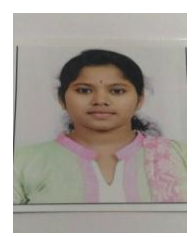

Ms. Rashmi H.C, 8TH Semester, Electronics and communication Dept., G Madegowda Institute of Technology, Bharathinagara (K M Doddi), Mandya.

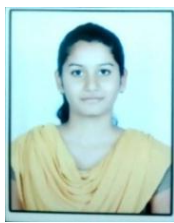

Ms. Sowmya N, 8TH Semester, Electronics and communication Dept., G Madegowda Institute of Technology, Bharathinagara (K M Doddi), Mandya.

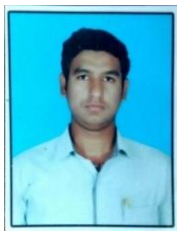

Mr. Shashidhar K.P, 8TH Semester, Electronics and communication Dept., G Madegowda Institute of Technology, Bharathinagara (K M Doddi), Mandya 